\title{
Lipids and lipoproteins in plasma from early pregnancy to postpartum and associations with ethnic background: a population-based cohort study from Norway.
}

\author{
Christin Waage $^{1}$, Ibrahimu Mdala ${ }^{1}$, Hein Stigum ${ }^{1}$, Anne Jenum ${ }^{1}$, Kåre Birkeland ${ }^{1}$, Nilam \\ Shakeel $^{1}$, Trond Michelsen ${ }^{1}$, Kåre Richardsen ${ }^{2}$, and Line Sletner ${ }^{1}$ \\ ${ }^{1}$ University of Oslo Faculty of Medicine \\ ${ }^{2}$ Oslo Metropolitan University
}

November 11, 2020

\begin{abstract}
Objective To describe ethnic differences in plasma lipid levels and their changes during pregnancy to postpartum. Design Population-based cohort study Setting Primary antenatal care, Eastern Oslo, Norway Population or Sample Healthy pregnant women, $59 \%$ with ethnic minority background $(\mathrm{n}=806)$. Methods Fasting lipid levels were measured at gestational week $(\mathrm{GW})$ 15, 28 and 14 weeks postpartum. We performed linear regression models and linear mixed models to explore the total effect of ethnicity on lipids, adjusting for GW or week postpartum, age and education. Main Outcome Measures Levels of triglycerides, HDL-, LDL- and total cholesterol. Results At GW 15, triglyceride levels were lower in women of African origin (1.03 mmol/mol $(95 \%$ CI: 0.90, 1.16)) and higher in women of South Asian $(1.42 \mathrm{mmol} / \mathrm{mol}(1.35,1.49))$ and East Asian origin $(1.58 \mathrm{mmol} / \mathrm{mol}$ $(1.43,1.73))$ compared with Western Europeans $(1.26 \mathrm{mmol} / \mathrm{mol}(1.20,1.32))$. Women of Asian and African origin had a smaller increase in triglycerides, LDL and total cholesterol from GW 15 to 28. At GW 28 LDL-cholesterol levels were lowest among East Asians at $(3.03 \mathrm{mmol} / \mathrm{mol}(2.72,3.34))$ compared with Western Europeans $(3.62 \mathrm{mmol} / \mathrm{mol}(3.50,3.74))$. Triglyceride and HDL-cholesterol levels were lower postpartum than in early pregnancy in all groups, but LDL-cholesterol levels were higher, except in Africans. South and East Asian women had lower HDL-cholesterol and higher triglycerides postpartum, while African women had lower triglyceride levels than Western Europeans. Conclusion We found significant differences in lipid levels and changes during pregnancy and the early postpartum period related to ethnic origin.
\end{abstract}

\section{Hosted file}

Manuscript_ethnicity_lipids_09.11.2020.pdf available at https://authorea.com/users/374910/ articles/492293-lipids-and-lipoproteins-in-plasma-from-early-pregnancy-to-postpartumand-associations-with-ethnic-background-a-population-based-cohort-study-from-norway

\section{Hosted file}

Table 1 and 2.xlsx available at https://authorea.com/users/374910/articles/492293-lipidsand-lipoproteins-in-plasma-from-early-pregnancy-to-postpartum-and-associations-withethnic-background-a-population-based-cohort-study-from-norway

\section{Hosted file}

Figure1a-d and 2a-d.10.06.2020.pdf available at https://authorea.com/users/374910/articles/ 492293-lipids-and-lipoproteins-in-plasma-from-early-pregnancy-to-postpartum-andassociations-with-ethnic-background-a-population-based-cohort-study-from-norway 